\title{
Research on the Characteristics of Leisure Cycling Tourism and Development Strategies
}

\author{
Liang Feng \\ Guilin Tourism University \\ Guilin, China \\ liangfeng@gltu.cn
}

\begin{abstract}
Cycling tour, as a green and healthy leisure travel mode, transforms a bike from a vehicle into a leisure travel tool, which is significantly meaningful for cycling culture. With application of literature review method to consult relevant materials, this paper expounds the understanding and development of cycling culture; starting with the cycling tour link view, it also discusses ideas of improving cycling tour, summarizes safety problems during the cycling tour, and puts forward effective proposals for promoting leisure cycling tour.
\end{abstract}

Keywords-Leisure Cycling Tourism; Cycling Culture; Characteristics; Development Strategies

\section{INTRODUCTION}

Cycling activity plays an important role during the development process of urban civilization. With the growth in people's material standard of living and development of economy, the function of bike has undergone a tremendous change, especially in foreign countries where using bicycle to tour, rather than just as a vehicle, has become a sport in leisure life [1]. At the present stage, western countries putting a great deal of effort into cycling tour, particularly in the USA and some European countries, makes cycling tour account for $10 \%$ of the tourism market, and in most areas cycling tour is regarded as a pillar industry. In recent years, environmental pollution has become more and more serious in China, so the call for environmental protection, low-carbon economy and green with no pollution is getting louder and louder, even rising to the state level, and General secretary Xi Jinping has stressed the importance of environmental protection at various meetings and inspections. For cycling tour acting as a new fashion of outdoor leisure sport, its way of exercise not only adapts with the modern economical and practical needs but also is a kind of low carbon environmental protection behavior with high flexibility and none pollution. Especially in the course of cycling tour, the feeling of becoming close to the earth and nature can't be replaced by other vehicles, benefiting the development of our economy and people's lives .Meanwhile, the study of leisure cycling tour also provides a theoretical basis for the rapidly developing cycling tour.

Author: Liang Feng (1983- ), male, born in Zibo in Shandong Province, doctor of science, lecturer, research area: leisure sports tourism industry.

\section{THINKING OF CYCLING CULTURE AND ITS PROMOTION SIGNIFICANCE}

\section{A. Understandings of Cycling Culture}

In recent years, with participation into national leisure sports, cycling tour has become more and more popular, and the new term "cycling culture" often can be seen. In daily life, cyclists are everywhere. With green environmental protection and low carbon travel concept as the principle, cycling has been accepted by and drawn attention of most people. For the bicycle industry, cycling culture is a manifestation not only of a product or individual business's behavior, but also of industry spirit. The popularity of this culture marks the transition from labor based science and technology to the modernized science and technology. Every cycling activity can be called a cultural tour. During cycling, people can enjoy the outdoor scenery, indulge themselves in the charm of mountains and rivers of the motherland, thereby deepening their understanding of history, culture and geography. Cycling also represents a lifestyle whose essence is to indulge in nature abandon the coziness and laziness of the modern civilization, feel the simplicity and purity, and appreciate the fun of wisdom and strength. This kind of cultural concept of environment and health has important significance in modern society, and embodies the characteristics of fitness, education and entertainment [2].

\section{B. Significance of Promoting the Development of Cycling culture}

Through the analysis of cycling culture, the important significance of promoting the development of cycling culture can be found out. The main points are as follows: first of all, promoting the development of cycling culture is conducive to enriching people's spiritual and cultural life. In the process of cycling tour, the cyclist can experience beauty and obtain more precious spiritual wealth, which gives more meaning to life. In outdoor cycling, people can escape from the pressure of life and work, and in the close contact with nature, feel the beauty of nature and realize the abundance of spiritual and cultural life. Secondly, it is beneficial to realize physical and mental integrity and personality development. In the outdoor cycling, cyclists need to comply with certain norms, and carry out orderly and purposeful activities, which fully embodies the characteristics of civilization. Outdoor cycling can influence 
people's spirit and ideology, reflect the progress of civilization, and play a very important role in cultivating talents and forming personality. Finally, promoting the development of cycling culture is of commercial values. In recent years, the leisure industry occupies a vital position in the development of national economy. Outdoor cycling exists as a special way of leisure tourism and its economic values gradually improve especially under the premise of rapid development of China's economy, when the national life standard increasingly improved, fitness and health have become the main theme of people's life, which creates a higher economic and social value [3].

\section{Features of Cycling Tour}

Cycling tour is a form of tour developed by bicycle, whose characteristics include the followings: first, cycling fitness is combined with the fitness exercise. Cycling is a tour form mainly relying on cyclists' physical energy to complete the whole journey, so that cyclists must have enough strength. In this way cyclists will get body building in the course of the tour, which is also a fundamental reason for people to participate in the cycling tour. In fact, there is no fixed boundary between bicycle sport enthusiasts and cycling tour enthusiasts, because bicycle sport enthusiasts prefer to travel by bicycle to enhance their physical strength. It is thus clear that there is a very close relationship between cycling tour and fitness; secondly, cycling tour is spontaneous and self-service. At present, cycling tour market system in our country is still defective, lacking relative cycling tour service projects, so most cycling tour activities are organized by cyclists themselves. In the initial stage of organizing cycling activities, cyclists are relatively few, and usually cycle individually. But as more and more cyclists join in, organized cycling tours are formed. In addition, cycling tour is self-driven. During the cycling journey, there are many scenic spots need to be decided whether to participate in by cyclists themselves., thereby planning the route and arranging equipment maintenance and accommodation work to facilitate the success of cycling tour activities; finally, communicate with good friends and exchange culture. Cycling tour evolves gradually from the basis of fitness, and attracts a large number of fans by its characteristics. Like in other activities, people often organize some cycling activities, such as travel at weekends or in holidays, gradually becoming a cultural phenomenon. Compared with the previous tour organizations, the members of the cycling tour organization are relatively fixed. They will spontaneously build a communication platform, chat by QQ or WeChat, and realize the richness of their leisure life [4].

\section{THOUGHTS OF DEVELOPING CYCLING TOUR}

\section{A. The characteristics of view of connection for cycling tour}

\section{1) Universality of connection}

It is known from the materialist dialectics that the link is universal, nothing in the world exists alone, and there is always some link among the things around it. Cycling tour is a very important part of the market economy. It belongs to a new type of tourism, which is not independent in society, but has corresponding links with the surroundings .The birth and development of cycling tour is based on the bicycle extreme sport. In 1960, a new type of sport from the western countries gradually sprang up. This kind of campaign uses bicycle as a specific tool, which contains a profound significance of sport, coupled with the western youth's individualism, hedonism, and heroism and so on, makes the cycling tour into a best way to express the spirit of postmodernism. Therefore, cycling tour is formed on the basis of the development of the times, has a certain degree of objectivity, and its development has a rule to follow.

\section{2) Objectivity of connection}

In this case, it does not mean that we can do nothing about the links between things, but we can change the form of things on the basis of their unique links to build a new link. As a new form of tourism, cycling tour will inevitably encounter some problems in the process of development, such as incomplete facilities in some cycling areas', badly-disposed garbage by cyclists. At this time, the subjective initiative should be given full play to build and improve the facilities [5].

\section{3) Diversity of connection}

Starting from materialist dialectics, things are everchanging and with a tremendous difference, so the links between things are also varied. In real life, people often see some superficial links, but ignore the nature of the links. Grasping the diversity of links can strengthen the correct understanding of things. Cycling tour's birth is not only related to practical reasons, but also because of the promotion of environmental protection consciousness. This kind of tourism form as a kind of fitness, indeed eases the traffic pressure, and attracts people's admiration and love, which achieves a rapid development of cycling tour.

\section{B. Tap resources, enrich the cycling culture}

Cycling tour is a kind of energy saving, environmental protection, low-carbon travel style, but also the main means for people to exercise and have leisure activities. In order to promote sound development of cycling tour, we need to fully tap resources and enrich cycling tour culture. Specifically start from the following aspects: firstly, manufacturers need to fully and indeed understand the bicycle riding culture, and actively participate in it. The first person who promotes and spreads cycling culture is the bicycle manufacturer, he needs to strengthen the importance of cycling culture in the manufacturing process, actively participate in the riding activities, and form a cycling upsurge in the society, in order to promote the sound development of cycling tour; secondly, organize various cycling activities. No matter local or national bicycle enterprises, in the premise of promoting the development of cycling tour, they should actively organize varied kinds of cycling activities, create cycling cultural atmosphere, and promote the development of tourism in popularizing the cycling culture at the same time; thirdly, advocate the new concepts of cycling tour culture. In the continuous development of cycling tour, we should strengthen the concept promotion of cycling tour culture, such as the concept of environmental protection, energy conservation, health and low carbon, to lay a solid foundation for the development of cycling tour; finally, make great efforts to do government work and get government's support. There is a 
close relationship between the support of the government and the development of cycling tour along with the cycling tour culture [6]. We should actively invite the government to participate in the cycling activities, and obtain government's support and approval to make the government play a leading role for the promotion of cycling tour culture.

\section{Consideration of safety problems in cycling tour}

1) Do a responsible job in cycling tour safety precaution Regional governments comprehend a lot about the existing local natural disasters and potential safety problems, and have more authoritative information, which plays a vital role in the safety of these cycling tourists and relates to whether cyclists can prepared well in advance and whether cyclists have a certain psychological envision of dangers. Therefore, before carrying out cycling tours, the government needs to focus on the weather forecast, forecast short-term weather conditions and contingent natural disasters, and inform cyclists by networks, televisions, radios and other forms to make the information transparent and reduce safety accidents. In addition, the tourism administrative departments at all levels should report cycling tour accidents and the causes of the accidents to the public by a variety of media forms, in order to make cyclists learn lessons and then pay attention to their own safety problems during the cycling tour.

\section{2) Polish tourism safety laws and regulations}

With the rapid development of cycling tour, China has promulgated some related laws and regulations for outdoor tourism. Although they can't directly avoid the dangers of cycling tours, but can guide the cyclists. On the basis of laws and regulations on tourism safety, the government and tourism organizations will strengthen the importance on cycling tour, take corresponding measures to realize standardizations of the organizations, require cyclists to actively safeguard their own safety based on the laws and regulations, thereby carrying out tour activities safely [7].

\section{3) Set up special lanes for cycling tours}

Some sports and recreational bicycle lanes in our country are designed on the basis of landscape roads and pedestrian roads, so there is no special bicycle lane yet. In order to promote the development of cycling tour, we can learn from foreign countries and Chinese Taiwan to set up dedicated bike lanes for cycling tours, which can not only reduce the friction between bicycles and other vehicles, but also fundamentally guarantee the safety of cyclists.

\section{CONCLUSION}

To sum up, as a kind of special travel experience, cycling tour can not only relax your mind and body, strengthen the communication, but also get the related benefits. Cycling tour is also conducive to enhancing the competitiveness of our country, but cyclists must pay attention to their own safety in the process of cycling, always keep a strong sense of security, organize and carry out cycling tours to promote tourism's sustainable development.

\section{ACKNOWLEDGMENT}

This paper is one of the phased achievements for the research subject: Research on Integrative Development of Guangxi leisure Sports Industry and Tourism Industry (17FTY004), planned and studied by Guangxi philosophy and Social Science; also is one of research results funded by Guilin Tourism University key discipline tourism management.

\section{REFERENCES}

[1] W. C. Chien, The Research on Leisure Sport Participating Motivation, Flow Experience and Well-Being-Case of biking Sport, Department of Businness Administration Chaoyang University of Technogy Thesis for the Degree of Master, 2015.

[2] X. Z. Zhou, H. Y. Yang, X.S. Liu. Analysis of travel motivation and tourism experience of Sichuan-Tibet cycling based on online travel notes. Tourism Overview, vol. 1, pp. 337-339, 2014.

[3] Y. X. Liu. Problems in bicycle riding tourism and suggestions for improvement Journal of Tianjin Trade Union Administrators' College, vol. 27, pp. 63-64. 2014.

[4] Z. M. Yan. Analysis of reasons and significance for riding tourism development from view of connection. New Economy, vol. 2, pp. 41-42, 2006.

[5] Z. M. Yan. The legitimate rights and interests of safety measures for cycling tourists. Knowledge Economy, vol. 1, pp. 85, 2006.

[6] X .K. Yang, M.j. Wang. R elationship Between Shared - oriented Cycling Culture Dissemination and Sports Tourism. Journal of Jixi University, vol. 16, pp. 28-30. 2016

[7] Y. H. Dong, Study on cycling tour experience. Tourism Overview, vol. 2, pp. $11+13,2016$. 